\title{
Estrogen-related and other disease diagnoses preceding Parkinson's disease
}

\author{
Jeanne C Latourelle ${ }^{1,2}$ \\ Merete Dybdahl ${ }^{3}$ \\ Anita L Destefano 1,4 \\ Richard H Myers' \\ Timothy L Lash ${ }^{2,3}$ \\ 'Department of Neurology, Boston \\ University School of Medicine, \\ Boston MA, USA; ${ }^{2}$ Department of \\ Epidemiology, Boston University \\ School of Public Health, Boston \\ MA, USA; ${ }^{3}$ Department of Clinical \\ Epidemiology, Aarhus University \\ Hospital, Aarhus, Denmark; \\ ${ }^{4}$ Department of Biostatistics, Boston \\ University School of Public Health, \\ Boston MA, USA
}

This article was published in the following Dove Press journal:

Clinical Epidemiology

26 May 2010

Number of times this article has been viewed

Purpose: Estrogen exposure has been associated with the occurrence of Parkinson's disease (PD), as well as many other disorders, and yet the mechanisms underlying these relations are often unknown. While it is likely that estrogen exposure modifies the risk of various diseases through many different mechanisms, some estrogen-related disease processes might work in similar manners and result in association between the diseases. Indeed, the association between diseases need not be due only to estrogen-related factors, but due to similar disease processes from a variety of mechanisms.

Patients and methods: All female Parkinson's disease cases between 1982 and 2007 ( $n=12,093$ ) were identified from the Danish National Registry of Patients, along with 10 controls matched by years of birth and enrollment. Conditional logistic regressions (CLR) were used to calculate risk of PD after diagnosis of the estrogen-related diseases, endometriosis and osteoporosis, conditioning on years of birth and enrollment. To identify novel associations between PD and any other preceding conditions, CLR was also used to calculate the odds ratios (ORs) for risk of PD for 202 different categories of preceding disease diagnoses. Empirical Bayes methods were used to identify the robust associations from the over 200 associations produced by this analysis.

Results: We found a positive association between osteoporosis and osteoporotic fractures and $\mathrm{PD}(\mathrm{OR}=1.18,95 \%$ confidence interval $[\mathrm{CI}]$ of $1.08-1.28)$, while a lack of association was observed between endometriosis and $\mathrm{PD}(\mathrm{OR}=1.37,95 \% \mathrm{CI} 0.99-1.90)$. Using empirical Bayes analyses, 24 additional categories of diseases, likely unrelated to estrogen exposure, were also identified as potentially associated with PD.

Conclusion: We identified several novel associations, which may provide insight into common causal mechanisms between the diseases or greater understanding of potential early preclinical signs of PD. In particular, the associations with several categories of mental disorders suggest that these may be early warning signs of PD onset or these diseases (or the causes of these diseases) may predispose to PD.

Keywords: Parkinson's disease, estrogen, osteoporosis, endometriosis, empirical bayes

\section{Introduction}

Parkinson's disease (PD) is a degenerative movement disorder that causes debilitating symptoms of tremor, rigidity, and bradykinesia usually occurring late in life. Sex is a consistently observed, but as of yet unexplained, risk factor for Parkinson's disease. Women are two-thirds as likely as age-matched men to develop Parkinson's disease. ${ }^{1}$ This decreased risk of PD in women, compared with men, has led to research into potential neuro-protective effects of estrogen on PD risk and treatment in particular. Improved motor function has been associated with estrogen treatment in studies
Correspondence: Jeanne Latourelle Department of Neurology, BUMC, 72 East Concord St, B-617, Boston, MA, 02119, USA

$\mathrm{Tel}+|617414| 199$

Fax +I 6176388086

Email jlatoure@bu.edu 
of women with PD. ${ }^{2-4}$ Furthermore, studies have shown some, although not all, factors associated with estrogen, such as hormone replacement therapy, ${ }^{5}$ length of fertile life, ${ }^{6}$ or receipt of hysterectomy ${ }^{7}$ are associated with PD risk. However, other studies have shown no, or an inverse association, to the same or similar factors. ${ }^{6-10}$

Estrogen exposure can not only be linked to Parkinson's disease, but other diseases as well; both as a potential risk factors or protective factors. As with Parkinson's disease, the underlying mechanism behind these relations is often unknown. Under the simplest scenarios, it could be expected that diseases associated with greater estrogen exposure would be associated with a lower risk of PD and vice versa. In reality, estrogen exposure probably modifies the risk of various diseases through different mechanisms and interactions with other susceptibility factors. Nevertheless, some estrogen-related disease processes may work in similar manners, resulting in an association between the diseases.

\section{Diseases related to increased estrogen exposure}

Diseases such as breast cancer, endometrial cancer, and endometriosis are associated with increased cumulative exposure to estrogen. ${ }^{11,12}$ We might expect to see a decreased incidence of PD in women suffering from these diseases, if the mechanisms through which estrogen modulates risk in any of those diseases are similar to the mechanisms in PD. Both breast and endometrial cancers have been examined as precedent conditions in case-control studies of PD, and no association has been found; ${ }^{13,14}$ however, many studies have reported overall reduced cancer rates or mortality in PD patients. ${ }^{15-20}$ These reports suggest a pathogenic link between PD and cancer that may supersede any estrogen-related factors. There have not, however, been any studies of endometriosis, ${ }^{11}$ as a precedent condition to PD.

\section{Diseases related to decreased estrogen exposure}

Osteoporosis is also associated with estrogen; reduced cumulative exposure to estrogen increases the risk of osteoporosis. ${ }^{21}$ Osteoporosis has been studied in patients with PD, partially because of the increased likelihood of falls in PD patients that lead to fractures. ${ }^{22}$ While the characteristic symptoms of postural instability in PD patients may explain the increased risk of fracture, lower bone mineral density (BMD) has also been observed in PD patients compared with age and sex matched controls, particularly in women. ${ }^{22,23}$ Suggested explanations for this difference include lower BMI, reduced exposure to sunlight, and lower vitamin D levels in people suffering from PD. Smoking, while related to both diseases, is a less likely explanation for the relationship as it may be associated with increased risk of osteoporosis, ${ }^{24,25}$ as compared with an association to decreased risk of PD. ${ }^{26} \mathrm{It}$ is also possible the association is due to a common estrogen related mechanism, increasing the risk of both diseases.

\section{Novel associations}

The idea of a common mechanism behind different disease processes can extend beyond estrogen related disease processes. While a number of genetic causes of PD have been identified these only account for a small percentage of cases and only very few environmental or modifiable risk factors of PD have been positively confirmed. ${ }^{27}$ Examining the entire range of preceding disease diagnoses in PD patients and controls may identify certain previously unsuspected risk factors for PD and provide insight as to common mechanisms behind diseases previously considered unrelated. Therefore, in this study, we will use a matched population based case-control study to compare the risk of PD after preceding diagnoses of the estrogen-related diseases endometriosis and osteoporosis, and also a wide range of disease diagnoses reported by female PD cases in the Danish National Registry of Patients.

\section{Methods}

\section{Population and sample}

The base population of this study is female Danish citizens identified in the Central Population Registry between 1982 and 2007. All Danish citizens are assigned a unique Central Population Registry (CPR) identification number which can be used to link the national registries. The Danish National Registry of Patients records all hospital admissions after 1977 and all outpatient and emergency visits after 1995. Each visit is identified with the CPR number of the patient, the date of the visit or hospital discharge, and a code for the primary diagnosis. ${ }^{28}$

A total of 12,247 female Parkinson's disease cases were identified by searching the Danish National Registry of Patients for a first instance of a PD diagnostic code (ICD-8: 342, ICD-10: G20) recorded between 1982 and 2007. Ten controls matched to each case by birth year, being alive and PD free at the time of PD diagnosis (index date) of the matched case, were selected using risk-set sampling from the Central Population Registry using their unique CPR number. Cases or controls were excluded when a diagnostic code for one of the following diseases was reported before the index date: Parkinsonism or secondary Parkinsonism $(n=159)$, unspecified motor neuron disease $(n=9)$, 
or unspecified hereditary neuromuscular disorder $(\mathrm{n}=5)$ to avoid misclassification. After these exclusions a final sample of 12,093 cases and 122,411 controls remained.

\section{Data collection}

The exposure variables relating to preceding disease diagnoses were also derived from the National Registry of Patients. For each case and control, the date and diagnostic code for all recorded hospital discharges or outpatient visits between 1977 and the index date of each subject were collected. This information was then used to create the estrogen related or other disease related exposure variables.

\section{Analytic variables}

First, exposure variables were created for two estrogen related diseases, endometriosis and osteoporosis. Subjects were coded as positive for endometriosis if an endometriosis diagnostic code (ICD-10: N80; ICD-8: 625.3) was recorded more than five years before their index date for the study. If no endometriosis diagnostic codes were recorded for a subject, or the codes were first recorded within five years of the index date, then the subject was coded as negative for endometriosis. The induction period of five years was selected to allow for some variation around an average lag of two years observed between the onset of the first symptoms of PD and clinical diagnosis of PD. ${ }^{29}$ The same method and induction time of five years was used to create two osteoporosis exposure variables. The first variable was defined strictly from diagnoses of osteoporosis appearing in the registry (Osteoporosis diagnostic codes: ICD-10: M80-M81; ICD-8:723). As osteoporosis may be significantly under-recorded in the registry of patients, a second variable was created, which included the above osteoporosis diagnostic codes as well as codes for hip, spine, and forearm fractures which are typically associated with osteoporosis (ICD-10: S120-S129, S220-S221, S320-S328, S520-S529, S720-S721; ICD-8:805, 808, 813, 820). ${ }^{30,31}$

The Danish National Registry of Patients includes diagnosis codes based on both ICD-8 (1977-1993) and ICD-10 (1993-present). There are over 10,000 different diagnostic codes used in the registry. To create exposure variables for all other preceding disease diagnoses, these individual ICD codes were grouped into disease categories based on the ICD-8 list of 300 causes for tabulation of hospital morbidity and the ICD-10 tabulation list for morbidity. All ICD codes are assigned to a single morbidity category in each of these tabulation lists, allowing a morbidity category to be identified for each ICD-8 and ICD-10 code from the registry of patients. The morbidity categories of the two tabulation lists were compared, and in many cases, the categories remained the same from ICD-8 to ICD-10 allowing the categories to be directly combined. In other cases, multiple categories from the ICD- 8 tabulation list needed to be combined into one category to be consistent with the ICD-10 tabulation list, and vice versa. Diagnostic codes and categories relating to external causes or injuries and routine hospital visits were excluded. A final list of 202 categories combining the ICD-10 and ICD-8 diagnostic codes was identified (see Appendix Table S1) and each case and control was defined as positive or negative for each disease category based on whether they had a recorded diagnostic code for that category more than five years before their index date.

\section{Analytic methods}

The distribution of ages and years of enrollment were determined for the cases and controls. The proportion of cases and controls with endometriosis and osteoporosis were calculated, and conditional logistic regression (CLR) was used to calculate the odds ratios (OR) for risk of $\mathrm{PD}$ after diagnosis of endometriosis and osteoporosis individually, conditioning on year of birth and year of enrollment. In addition, the CLRs were repeated stratifying the sample into older ( $>75$ years) and younger age-at-index date ( $\leq 75$ years) groups. To identify new associations between PD and other preceding conditions, CLR was similarly used to calculate the OR for risk of PD associated with each of the 202 morbidity categories, conditioning on year of birth and year of enrollment.

In order to identify the robust associations from the over 200 associations produced by this analysis, Empirical

Table I Distributions of ages and year of enrollment for female Parkinson's disease cases identified from the Danish National Registry of Patients between 1982 and 2007 and matched controls

\begin{tabular}{|c|c|c|c|}
\hline \multicolumn{2}{|c|}{ All } & $\begin{array}{l}\text { Cases } \\
\mathrm{n}=\mid \mathbf{I} 2093\end{array}$ & $\begin{array}{l}\text { Controls } \\
n=|224| \mid\end{array}$ \\
\hline \multicolumn{4}{|c|}{ Age range, years } \\
\hline & $<=40$ & $55(<1 \%)$ & $546(<1 \%)$ \\
\hline & $4 I-50$ & 145 (I\%) & 1505 (1\%) \\
\hline & $5 I-60$ & 557 (5\%) & $5527(5 \%)$ \\
\hline & $6 I-70$ & 1972 (16\%) & $20|3|(16 \%)$ \\
\hline & $7 I-80$ & $5404(45 \%)$ & 54594 (45\%) \\
\hline & $81-90$ & 3709 (31\%) & 37565 (31\%) \\
\hline & $90+$ & $25 \mathrm{I}(2 \%)$ & $2543(2 \%)$ \\
\hline \multicolumn{4}{|c|}{ Date of admittance } \\
\hline \multicolumn{4}{|c|}{ Hospital visits } \\
\hline & $1982-1987$ & $3533(29 \%)$ & 35349 (29\%) \\
\hline & 1988-1994 & $3303(27 \%)$ & 33050 (27\%) \\
\hline \multirow{2}{*}{\multicolumn{4}{|c|}{$\begin{array}{l}\text { Hospital, emergency } \\
\text { and outpatient visits }\end{array}$}} \\
\hline & & & \\
\hline & $|995-200|$ & 3127 (26\%) & 32023 (26\%) \\
\hline & $2002-2007$ & $2130(18 \%)$ & 21989 (18\%) \\
\hline
\end{tabular}


Bayes (EB) methods ${ }^{32}$ were used to shrink the effect for each morbidity-PD association towards the null in proportion to the variance of the OR. Fifty-five morbidity categories with fewer than five cases were excluded from the EB analysis to provide a baseline level of stability in the estimates. The 147 remaining estimates were used to calculate adjusted $P$-values and ORs for each category.

\section{Results}

The distribution of ages and year of enrollment of the final sample of 12,093 cases and 122,411 controls is shown in Table 1. The average age of diagnosis for the PD cases or enrollment for the matched controls was 75 years (standard deviation [SD] = 9.2). The average time from the beginning of precedent disease recordings in the Danish National Registry of Patients in 1977 until enrollment in the study was 17 years $(\mathrm{SD}=7.3)$.

Endometriosis shows a marginal association with increased risk of $\mathrm{PD}$ in the total sample with an OR of 1.37 (95\% confidence interval [CI] 0.99-1.90, Table 2a). Stratifying by age at index date suggests that this marginal increase is driven by a stronger positive association with $\mathrm{PD}$ in women age 75 and under, with an OR of 1.49 (95\% CI of 1.05-2.11), while in women over the age of 75 there is no increase in risk of $\mathrm{PD}(\mathrm{OR}=0.9,95 \% \mathrm{CI}$ of $0.36-2.24)$. A test of homogeneity of the odds ratios, however, did not show a significant difference between the two groups $(P=0.31)$.

Diagnosis of osteoporosis appears to have no effect on later risk of $\mathrm{PD}$, either in the entire sample or in either age strata, with ORs very close to the null in all cases
(Table 2b). Table 2c shows the same results, however, including osteoporotic fractures as well as osteoporosis diagnoses in the definition of the exposure. This definition shows a much higher prevalence of osteoporosis in the population and shows a slight increased risk of PD in women with osteoporosis with an OR of 1.18 (95\% CI of 1.08-1.28). This risk appears to be somewhat greater in women age 75 and under at index date, with an OR of 1.35 (95\% CI of 1.14-1.61), but also appears in women over the age of 75 $(\mathrm{OR}=1.13,95 \% \mathrm{CI}$ of $1.03-1.24)$.

For each of the 147 morbidity categories an effect estimate (the natural $\log$ of the odds ratio, (lnOR) was obtained. Figure 1 shows a histogram of these 147 observed effect estimates and the effect estimates are normally distributed. In any random set of predictors, we might expect to see a normal distribution centered around the null with an equal number of positively associated predictors and negatively associated predictors. In this case, however, the distribution of effect sizes is not centered on the null value of zero. Many more morbidity categories were positively associated than were negatively associated, with a mean effect size across all 147 categories of 0.22 , SD of 0.25 and a range from -0.53 to 1.15 .

Empirical Bayes adjustment was used to shrink the 147 effect estimates towards the mean estimate to identify the robust associations. After adjustment, 23 categories showed an association to PD with $P<0.05$. The original and adjusted ORs and the adjusted $P$-value for these 23 categories are shown in Table 3, grouped together by similar pathways or outcomes. Consistent with the distribution seen in Figure 1,

Table 2 Numbers of female Parkinson's disease cases and matched controls with exposure to the estrogen-related diseases, along with ORs and $95 \%$ confidence intervals from conditional logistic regression, conditioning on age and birth year A. Endometriosis B. Osteoporosis by diagnosis C. Osteoporosis by diagnosis or osteoporotic fracture

\begin{tabular}{|c|c|c|c|c|c|c|}
\hline & Total sample & & Age $\leq 75$ & & Age $>75$ & \\
\hline $\mathbf{A}$ & Endometriosis & No endometriosis & Endometriosis & No endometriosis & Endometriosis & No endometriosis \\
\hline Cases & 42 & $|205|$ & 37 & 5056 & 5 & 6995 \\
\hline Controls & 315 & 122096 & 258 & 51438 & 57 & 70658 \\
\hline OR $(95 \% \mathrm{Cl})$ & 1.37 (0.99-I.90) & & $1.49(1.05-2.11)$ & & $0.90(0.36-2.24)$ & \\
\hline B & Osteoporosis & No osteoporosis & Osteoporosis & No osteoporosis & Osteoporosis & No osteoporosis \\
\hline Cases & 108 & I 1985 & 16 & 5077 & 92 & 6908 \\
\hline Controls & 1117 & 121294 & 185 & 51511 & 932 & 69783 \\
\hline OR $(95 \% \mathrm{Cl})$ & $0.99(0.8|-| .20)$ & & $0.89(0.53-1.49)$ & & $\mathrm{I} .00(0.8 \mathrm{I}-\mathrm{I} .25)$ & \\
\hline C & $\begin{array}{l}\text { Osteoporosis } \\
\text { including } \\
\text { osteoporotic } \\
\text { fracture }\end{array}$ & $\begin{array}{l}\text { No osteoporosis } \\
\text { including } \\
\text { osteoporotic } \\
\text { fracture }\end{array}$ & $\begin{array}{l}\text { Osteoporosis } \\
\text { including } \\
\text { osteoporotic } \\
\text { fracture }\end{array}$ & $\begin{array}{l}\text { No osteoporosis } \\
\text { including } \\
\text { osteoporotic } \\
\text { fracture }\end{array}$ & $\begin{array}{l}\text { Osteoporosis } \\
\text { including } \\
\text { osteoporotic } \\
\text { fracture }\end{array}$ & $\begin{array}{l}\text { No osteoporosis } \\
\text { including } \\
\text { osteoporotic } \\
\text { fracture }\end{array}$ \\
\hline Cases & 683 & $1|4| 0$ & 149 & 4944 & 534 & 6466 \\
\hline Controls & 6005 & I I6406 & $|15|$ & 50545 & 4854 & 65861 \\
\hline OR $(95 \% \mathrm{Cl})$ & I.I8 (I.08-I.28) & & $1.35(1.14-1.6 I)$ & & I.I3 (I.03-I.24) & \\
\hline
\end{tabular}

Abbreviations: $\mathrm{Cl}$, confidence interval; OR, odds ratio. 


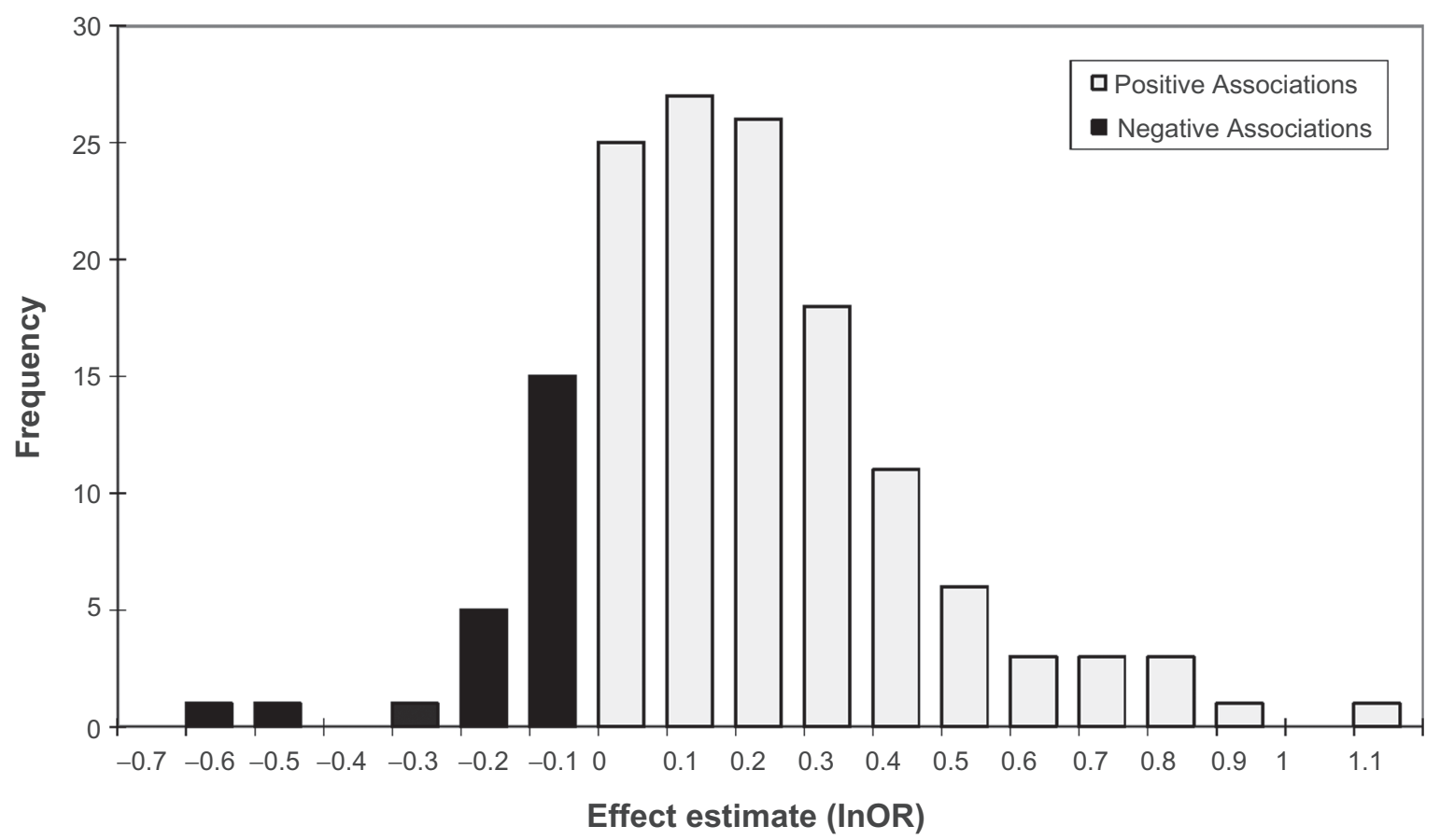

Figure I The distribution of effect estimates produced by conditional logistic regression for female Parkinson's disease cases and matched controls on each of I 47 morbidity categories derived from the Danish National Registry of Patients diagnostics codes is shown. Effect estimates representing a positive association are shown in grey, while negative associations are shown in black.

Abbreviation: InOR, the natural log of the odds ratio.

these 23 robust associations were in a casual direction, not protective. The association with the lowest $P$-value after adjustment was with neurotic, somatoform, and stress related disorders, which had an adjusted OR of 2.16 and adjusted $P$-value of $1.5 \mathrm{E}-07$.

The 10 morbidity categories with the most protective adjusted ORs are shown in Table 4. Only three morbidity categories showed any protective effect after adjustment and none had $P<0.05$. Original and EB adjusted results for all categories are shown in the Appendix Table S2.

\section{Discussion}

Endometriosis did not show the hypothesized protective association with PD, in fact the younger category of women demonstrated a moderately increased risk of PD associated with endometriosis in this study. These results suggest that the observed estrogen related effects in these two diseases likely do not work through similar mechanisms. One point to consider is that endometriosis is primarily diagnosed in young women, and is dependent on high circulating levels of estrogen. ${ }^{33} \mathrm{PD}$ is primarily seen in older women and may be more affected by cumulative estrogen exposure rather than current estrogen levels, ${ }^{6,7}$ suggesting different estrogen related mechanisms of action. Estrogen naturally occurs in many forms, including 17- $\beta$ estradiol, estrone, and estriol, which circulate at different levels as women age. ${ }^{34-36}$ In older women, circulating levels of estradiol, the most common estrogen during the reproductive years, decrease and estrone becomes the most common estrogen. Therefore, it is also possible that the estrogen related effects of these two diseases may be specifically related to different forms of the hormone.

Another factor may be the limited control for confounding effects of treatments or other by-products of the initial disease process in this study. Women suffering from endometriosis may be treated with oral contraceptives or in severe cases by hysterectomy, which have both been observed in other studies to be associated with increased risk of PD. ${ }^{7,37}$ Further study, including prescription and treatment information, would be warranted for these findings.

It is also of interest to note that the positive association appears to be only in women enrolled into the study before the age of 75. As endometriosis is most commonly diagnosed at a much younger age than PD, it is very likely that the older age group has increased misclassification due to the left censoring of the exposure data at 1977. It is possible this apparent difference in the ORs is due to a bias of the observed effect toward the null in the older group.

On the other hand, osteoporosis (defined with osteoporotic fractures) showed an increased risk of later PD diagnosis in both older and younger women. This result is consistent with the known protective effects of estrogen on both diseases. Notably, unlike endometriosis, both PD and osteoporosis 
Table 3 After EB adjustment, 23 out of 147 tested morbidity categories showed association to PD in the conditional logistic regression analysis with an adjusted $P$-value less than 0.05

\begin{tabular}{|c|c|c|c|c|c|}
\hline Grouping & Morbidity category & \# Cases & $\begin{array}{l}\text { Original } \\
\text { OR }\end{array}$ & $\begin{array}{l}\text { EB-Adjusted } \\
\text { OR }\end{array}$ & $\begin{array}{l}\text { EB-Adjusted } \\
\text { P-value }\end{array}$ \\
\hline Psychological or & Neurotic, stress-related and somatoform disorders & 278 & 2.35 & 2.16 & I.5E-07 \\
\hline \multirow[t]{5}{*}{ Behavioral disorders } & Depression & 77 & 2.02 & 1.7 & 0.001 \\
\hline & Alcohol-, drug-abuse-related disease & 104 & 1.85 & 1.65 & 0.002 \\
\hline & Other mental and behavioral disorders & 99 & 1.72 & 1.56 & 0.006 \\
\hline & Mood [affective] disorders & 34 & 2.37 & 1.65 & 0.006 \\
\hline & Other diseases of the nervous system & 314 & 1.64 & 1.59 & 0.001 \\
\hline Neurological & Mental retardation & 22 & 3.15 & 1.68 & 0.007 \\
\hline \multirow[t]{3}{*}{ disorders } & Epilepsy & 95 & 1.67 & 1.52 & 0.009 \\
\hline & Migraine & 75 & 1.52 & 1.41 & 0.038 \\
\hline & Alcohol-, drug-abuse-related disease & 104 & 1.85 & 1.65 & 0.002 \\
\hline Alcohol-related & Acute pancreatitis and other diseases of the pancreas & 62 & 1.84 & 1.57 & 0.008 \\
\hline \multirow[t]{4}{*}{ disorders } & Other diseases of liver and gallbladder & 95 & 1.48 & 1.4 & 0.037 \\
\hline & Gastritis and duodenitis & 171 & 1.39 & 1.36 & 0.042 \\
\hline & Rheumatism & 327 & 1.56 & 1.52 & 0.004 \\
\hline & Cystitis & 307 & 1.52 & 1.48 & 0.006 \\
\hline Inflammatory & Acute pancreatitis and other diseases of the pancreas & 62 & 1.84 & 1.57 & 0.008 \\
\hline \multirow[t]{3}{*}{ disorders } & Other infectious and parasitic diseases & 64 & 1.58 & $\mathrm{I} .44$ & 0.032 \\
\hline & Gastritis and duodenitis & 171 & 1.39 & 1.36 & 0.042 \\
\hline & lodine deficiency-related thyroid disorders & 210 & 1.45 & $\mathrm{I} .4 \mathrm{I}$ & 0.02 \\
\hline Gastro-intestinal, & Other endocrine, nutritional and metabolic disorders & 302 & 1.38 & 1.36 & 0.034 \\
\hline \multirow[t]{3}{*}{ nutritional disorders } & Gastritis and duodenitis & 171 & 1.39 & 1.36 & 0.042 \\
\hline & Angina pectoris & 326 & 1.48 & 1.45 & 0.01 \\
\hline & Other diseases of the circulatory system & 51 & 1.8 & 1.52 & 0.016 \\
\hline \multirow[t]{4}{*}{ Uncategorized } & Diabetes mellitus & 303 & $1.4 \mathrm{I}$ & 1.39 & 0.023 \\
\hline & Respiratory tuberculosis & 27 & 2.12 & 1.53 & 0.024 \\
\hline & Other ischemic heart diseases & 396 & 1.37 & 1.36 & 0.031 \\
\hline & Disorders of menstruation & 802 & 1.32 & 1.32 & 0.045 \\
\hline
\end{tabular}

Notes: The number of exposed cases, original $O R$, adjusted $O R$, and adjusted $P$-value for each category are shown. Morbidity categories are grouped with related categories, and can appear in more than one grouping.

Abbreviations: PD, Parkinson's disease; $\mathrm{Cl}$, confidence interval; OR, odds ratio; EB, empirical Bayes adjustment.

tend to occur later in life and may be more likely to work through similar processes. Osteoporosis defined strictly by the registry diagnoses, not including osteoporotic related fractures, did not show any association to later PD risk. This null result could be due to a number of reasons. Diagnoses of osteoporosis are under-reported in the Danish registry of patients, with incident rates approximately $8 \%$ of expected, and often patients whose osteoporosis is first identified by an osteoporotic fracture are listed only under the fracture codes. ${ }^{31}$ Therefore, using only osteoporosis diagnostic codes likely results in severe misclassification, particularly among younger women. If this misclassification was non-differential,

Table 4 The 10 disease categories with the lowest EB adjusted ORs for PD from the 147 conditional logistic regression analyses are shown with the number of exposed cases, original OR, adjusted $O R$ and adjusted $P$-value

\begin{tabular}{|c|c|c|c|c|}
\hline Morbidity category & \# Cases & $\begin{array}{l}\text { Original } \\
\text { OR }\end{array}$ & $\begin{array}{l}\text { EB-Adjusted } \\
\text { OR }\end{array}$ & $\begin{array}{l}\text { EB-Adjusted } \\
P \text {-value }\end{array}$ \\
\hline Retinal detachments and breaks & 23 & 0.59 & 0.93 & 0.70 \\
\hline Other diseases of arteries, arterioles and capillaries & 97 & 0.84 & 0.93 & 0.67 \\
\hline Malignant neoplasm of cervix uteri & 25 & 0.65 & 0.95 & 0.79 \\
\hline Pregnancies with abortive outcome & 119 & 0.94 & 1.02 & 0.92 \\
\hline Paralytic ileus and intestinal obstruction without hernia & 61 & 0.92 & 1.03 & 0.87 \\
\hline Bronchitis, emphysema and other chronic obstructive pulmonary diseases & 238 & 1.00 & 1.03 & 0.82 \\
\hline Delivery without mention of complication & 72 & 0.92 & 1.04 & 0.84 \\
\hline Osteoporosis (not including osteoporotic fracture) & 108 & 0.99 & 1.05 & 0.78 \\
\hline Crohn's disease and ulcerative colitis & 36 & 0.88 & 1.05 & 0.79 \\
\hline Other malignant neoplasms of female genital organs & 25 & 0.82 & 1.05 & 0.79 \\
\hline
\end{tabular}

Abbreviations: PD, Parkinson's disease; $\mathrm{Cl}$, confidence interval; OR, odds ratio; EB, empirical Bayes adjustment. 
as expected given the design, it could result in a substantial bias towards the null, explaining the differing results between the two definitions.

However, an alternative explanation could be due to increased fractures in PD cases due to early PD symptoms of postural instability. Postural instability is a classic symptom of PD and can lead to falls in PD cases; one study found a $38 \%$ risk of falling in PD cases. ${ }^{38}$ However, postural instability is usually characteristic of later stages of PD, with the time until first fall an average of 9 years after the onset of the earliest symptoms, which are typically tremor or bradykinisia. ${ }^{39,40}$ Therefore, it is unlikely that a large number of PD cases would have a PD-related fall five or more years before first appearance of a PD code. Nevertheless, the observed association is small $(\mathrm{OR}=1.18)$ and possible bias should be considered, especially as it may point to a longer preclinical, symptomatic phase of PD than often considered.

Empirical Bayes adjustment was used to identify novel associations warranting further investigation from analyses of 147 selected morbidity categories identified from the national registry of patients. Using a cutoff of an EB adjusted $P$-value of 0.05 identified 23 morbidity categories of interest. In comparison, using the same $P$-value cutoff on the unadjusted results would identify 61 categories for follow-up and using a Bonferroni $P$-value correction for 147 contrasts $(P=0.00034)$ would have resulted in the identification of 24 categories of interest (Appendix Table S2). The EB method showed a similar reduction in potential false-positive findings as the conventional method, while likely improving the accuracy of the process by using the observed variance of the data to provide more precise estimates of association.

Many of the strongest associations identified after the EB analysis are psychological or neurological disorders (Table 3). Some of these associations, particularly to certain neurological diseases, may be due to long-term misdiagnoses before identifying the case as PD. The strong associations seen between PD and neurotic disorders, depression, and other mental and behavioral disorders more than 5 years before PD diagnosis may suggest that psychological symptoms; which are known to be associated with both PD and dopamine levels, may be noticed in PD patients long before any traditional clinical signs of the disease manifest. Alternatively, this association could also be consistent with a common mechanism causing a susceptibility to loss of neurotransmitters. Examination of mental disorders before PD have shown consistent associations with increased risk of PD in both case-control and cohort studies. ${ }^{41}$ A study examining both depression and anxiety disorders before PD found that the increased risk of PD seen after depression was attenuated when restricting depression diagnosis to more than 5 years in the past. Anxiety disorders however, continued to predict increased PD risk even when restricting to a lag of over 20 years between the diagnoses. ${ }^{42}$ This pattern suggests depressive disorders may be more likely to represent early signs of $\mathrm{PD}$, while anxiety disorders may be more likely to be associated with a casual mechanism.

Several of the other most strongly associated preceding conditions could be grouped together with other related conditions. Alcohol abuse, as well as liver disease and pancreatitis (diseases often associated with alcohol abuse), all show a strong increased risk of subsequent PD. Cirrhosis of the liver, which is often caused by alcohol abuse, has been associated with symptoms of Parkinsonism, and may be associated with the accumulation of excess levels of manganese which is related to the liver disease..$^{43}$ These symptoms are distinct from idiopathic $\mathrm{PD}$, although they may cause misclassification of PD cases that would bias the results for these associations, particularly in the liver disease category.

Alcohol use and abuse has been reported in some studies as protective of PD. ${ }^{44-46}$ Nevertheless, the finding of alcohol abuse related diseases positively associated with PD in this sample of Danish women is consistent with a prospective cohort study conducted in the United Kingdom, which found no overall association between alcoholism and PD, although the study did find an OR of 2.7 (95\% CI 1.1-6.8) when only women were studied, albeit in a small number of cases ${ }^{47}$ Taken together, these findings are suggestive that the effect of alcohol on PD risk may be sex-specific. Interestingly, several studies have found an association between alcohol consumption and elevated circulating estrogen levels in premenopausal women and postmenopausal women using hormone replacement therapy (HRT) and not using HRT. ${ }^{48-51}$

Also of interest is the finding that several different inflammatory diseases (eg, rheumatism, cystitis, acute pancreatitis among others) associated with later risk of PD. Inflammation has been a topic of considerable study in the pathogenesis of PD, as inflammatory markers have been observed in the brains of PD patients. ${ }^{52}$ While the mechanism is uncertain, and continued investigation is examining whether this inflammation is a cause or a by-product of PD related neurodegeneration, these associations to inflammation related (albeit very clinically diverse) diseases could be suggestive of a common inflammation related mechanism. Finally, we also note several diseases related to the gastrointestinal system and malnutrition associated with increased PD risk, which may be suggestive of a malabsorption related mechanism for PD risk. 
The distribution of effects seen across the 147 morbidity categories were substantially skewed towards associations with increased risk (Figure 1). Very few associations showed a protective effect. Nevertheless, the most protective or least causal associations (identified in Table 4) are not unexpected findings. The known protective effect of smoking on PD is a likely reason for the nearly negative association between bronchitis, emphysema, and other chronic obstructive pulmonary diseases and PD. Several of the least causally associated categories are estrogen related, including: delivery without complications; pregnancies that had an abortive outcome; and malignant neoplasm of the cervix uteri and other female genital organs, consistent with the original hypothesis of the study, that conditions associated with estrogen may be associated with decreased risk of PD. The lack of protective associations observed in this study may be due to a form of Berkson's bias in this sample. Berkson's selection bias is based on the idea that people with two or more medical conditions are more likely to be hospitalized than people with only one medical condition. Higher rates of disease diagnosis may occur in people who seek out medical attention more frequently.

\section{Strengths and limitations}

This study is based on national registry data, and thus includes all female PD cases in Denmark, diagnosed between 1982 and 2007, with well-matched controls. All exposure data are also derived from the registry and are not subject to recall bias. Nevertheless, the results of these studies are limited in the ability to control for confounding, in particular by treatments associated with the preceding disease as well as important risk modifiers of PD and other diseases such as smoking. In addition, the use of hospital morbidity categories may provide less than ideal definitions for exposure categories. In some cases, rarer or less well understood diseases with very different causes and etiologies may be combined into one morbidity category. The study is further complicated by the uncertain latent and induction period for PD, although the insight into potential early preclinical signs of PD may be of equal importance to understanding the disease process as the understanding of causal mechanisms. It is not possible to distinguish whether observed associations arise from a causal effect of the preceding disease or from common causal mechanisms underlying the etiology of both PD and the paired diseases.

\section{Conclusion}

In conclusion, the findings of a positive association between osteoporosis and PD and the relatively negative association seen to estrogen related morbidity categories in the EB analysis provides further evidence of estrogen related neuro-protection against PD. The finding of no association between endometriosis and PD, however, does not support this protective relationship. The lack of association between PD and endometriosis may indicate different estrogenic effects on the disease process; for example, a neuro-protective mechanism based on long-term estrogen exposure and less dependent on high levels of estrogen at a given time, which may be more influential in endometriosis. In addition, several novel associations to PD were identified using EB analysis, which may lead to future insight into the disease process.

\section{Acknowledgments}

This study was supported, in part, by PHS grant R01 NS36711-09 'Genetic Linkage Study in PD', the Robert P. \& Judith N. Goldberg Foundation and the Aarhus University Hospital Department of Clinical Epidemiology's Research Foundation.

\section{Disclosures}

The authors reports no conflicts of interest relevant to this work.

\section{References}

1. Bower JH, Maraganore DM, McDonnell SK, Rocca WA. Incidence and distribution of parkinsonism in Olmsted County, Minnesota, 1976-1990. Neurology. 1999;52(6):1214-1220.

2. Nicoletti A, Arabia G, Pugliese P, et al. Hormonal replacement therapy in women with Parkinson disease and levodopa-induced dyskinesia: a crossover trial. Clin Neuropharmacol. 2007;30(5):276-280.

3. Blanchet PJ, Fang J, Hyland K, Arnold LA, Mouradian MM, Chase TN. Short-term effects of high-dose 17beta-estradiol in postmenopausal PD patients: a crossover study. Neurology. 1999;53(1):91-95.

4. Saunders-Pullman R, Gordon-Elliott J, Parides M, Fahn S, Saunders HR, Bressman S. The effect of estrogen replacement on early Parkinson's disease. Neurology. 1999;52(7):1417-1421.

5. Currie LJ, Harrison MB, Trugman JM, Bennett JP, Wooten GF. Postmenopausal estrogen use affects risk for Parkinson disease. Archives of Neurology. 2004;61(6):886-888.

6. Ragonese P, D’Amelio M, Salemi G, et al. Risk of Parkinson disease in women: effect of reproductive characteristics. Neurology. 2004;62(11):2010-2014.

7. Benedetti MD, Maraganore DM, Bower JH, et al. Hysterectomy, menopause, and estrogen use preceding Parkinson's disease: an exploratory case-control study. Mov Disord. 2001;16(5):830-837.

8. Popat RA, Van Den Eeden SK, Tanner CM, et al. Effect of reproductive factors and postmenopausal hormone use on the risk of Parkinson disease. Neurology. 2005;65(3):383-390.

9. Ascherio A, Chen H, Schwarzschild MA, Zhang SM, Colditz GA, Speizer FE. Caffeine, postmenopausal estrogen, and risk of Parkinson's disease. Neurology. 2003;60(5):790-795.

10. Simon KC, Chen H, Gao X, Schwarzschild MA, Ascherio A. Reproductive factors, exogenous estrogen use, and risk of Parkinson's disease. Mov Disord. 2009;24(9):1359-1365.

11. Bertelsen L, Mellemkjaer L, Frederiksen K, et al. Risk for breast cancer among women with endometriosis. Inter J Cancer. 2007; 120(6):1372-1375. 
12. Pike MC, Ross RK. Progestins and menopause: epidemiological studies of risks of endometrial and breast cancer. Steroids. 2000; 65(10-11):659-664.

13. Elbaz A, Peterson BJ, Yang P, et al. Nonfatal cancer preceding Parkinson's disease: a case-control study. Epidemiology. 2002; 13(2):157-164.

14. Olsen JH, Friis S, Frederiksen K, McLaughlin JK, Mellemkjaer L, Moller H. Atypical cancer pattern in patients with Parkinson's disease. Brit J Cancer. 2005;92(1):201-205.

15. Inzelberg R, Jankovic J. Are Parkinson disease patients protected from some but not all cancers? Neurology. 2007;69(15):1542-1550.

16. Doshay LJ. Problem situations in the treatment of paralysis agitans. J Am Med Assoc. 1954;156(7):680-684.

17. Hoehn MM, Yahr MD. Parkinsonism: onset, progression and mortality. Neurology. 1967;17(5):427-442.

18. Jansson B, Jankovic J. Low cancer rates among patients with Parkinson's disease. Annals of Neurology. 1985;17(5):505-509.

19. Minami Y, Yamamoto R, Nishikouri M, Fukao A, Hisamichi S. Mortality and cancer incidence in patients with Parkinson's disease. J Neurol. 2000;247(6):429-434.

20. Moller H, Mellemkjaer L, McLaughlin JK, Olsen JH. Occurrence of different cancers in patients with Parkinson's disease. BMJ. 1995;310(6993):1500-1501.

21. Khan A. Premenopausal women and low bone density. Canadian Family Physician Medecin de Famille Canadien. 2006;52:743-747.

22. Vaserman N. Parkinson's disease and osteoporosis. Joint Bone Spine. 2005;72(6):484-488

23. Schneider JL, Fink HA, Ewing SK, Ensrud KE, Cummings SR. The association of Parkinson's disease with bone mineral density and fracture in older women. Osteoporos Int. 2008;19(7):1093-1097.

24. Waugh EJ, Lam MA, Hawker GA, et al. Risk factors for low bone mass in healthy 40-60 year old women: a systematic review of the literature. Osteoporos Int. 2009;20(1):1-21.

25. Law MR, Hackshaw AK. A meta-analysis of cigarette smoking, bone mineral density and risk of hip fracture: recognition of a major effect. BMJ. 1997;315(7112):841-846.

26. Hernan MA, Takkouche B, Caamano-Isorna F, Gestal-Otero JJ. A meta-analysis of coffee drinking, cigarette smoking, and the risk of Parkinson's disease. Ann Neurol. 2002;52(3):276-284.

27. Lees AJ, Hardy J, Revesz T. Parkinson's disease. Lancet. 2009; 373(9680):2055-2066.

28. Andersen TF, Madsen M, Jorgensen J, Mellemkjoer L, Olsen JH. The Danish National Hospital Register. A valuable source of data for modern health sciences. Dan Med Bull. 1999;46(3):263-268.

29. Maher NE, Golbe LI, Lazzarini AM, et al. Epidemiologic study of 203 sibling pairs with Parkinson's disease: the GenePD study. Neurology. 2002;58(1):79-84.

30. Melton LJ 3rd, Thamer M, Ray NF, et al. Fractures attributable to osteoporosis: report from the National Osteoporosis Foundation. J Bone Mineral Res. 1997;12(1):16-23.

31. Vestergaard P, Rejnmark L, Mosekilde L. Osteoporosis is markedly underdiagnosed: a nationwide study from Denmark. Osteoporos Int. 2005;16(2):134-141.

32. Steenland K, Bray I, Greenland S, Boffetta P. Empirical Bayes adjustments for multiple results in hypothesis-generating or surveillance studies. Cancer Epidemiol Biomarkers Prev. 2000;9(9):895-903.

33. Bulun SE. Endometriosis. N Engl J Med. 2009;360(3):268-279.
34. Baird DT, Fraser IS. Blood production and ovarian secretion rates of estradiol-17 beta and estrone in women throughout the menstrual cycle. J Clin Endocrinol Metab. 1974;38(6):1009-1017.

35. Flood C, Pratt JH, Longcope C. The metabolic clearance and blood production rates of estriol in normal, non-pregnant women. $\mathrm{J}$ Clin Endocrinol Metab. 1976;42(1):1-8.

36. Gruber CJ, Tschugguel W, Schneeberger C, Huber JC. Production and actions of estrogens. $N$ Engl J Med. 2002;346(5):340-352.

37. Treatment of pelvic pain associated with endometriosis. Fertil Steril. 2008;90 Suppl 5:S260-S269.

38. Koller WC, Glatt S, Vetere-Overfield B, Hassanein R. Falls and Parkinson's disease. Clin Neuropharmacol. 1989;12(2):98-105.

39. Williams DR, Watt HC, Lees AJ. Predictors of falls and fractures in bradykinetic rigid syndromes: a retrospective study. J Neurol Neurosurg Psychiatry. 2006;77(4):468-473.

40. Jankovic J. Parkinson's disease: clinical features and diagnosis. J Neurol Neurosurg Psychiatry. 2008;79(4):368-376.

41. Ishihara L, Brayne C. A systematic review of depression and mental illness preceding Parkinson's disease. Acta Neurol Scand. 2006; 113(4):211-220.

42. Shiba M, Bower JH, Maraganore DM, et al. Anxiety disorders and depressive disorders preceding Parkinson's disease: a case-control study. Mov Disord. 2000;15(4):669-677.

43. Burkhard PR, Delavelle J, Du Pasquier R, Spahr L. Chronic parkinsonism associated with cirrhosis: a distinct subset of acquired hepatocerebral degeneration. Archives of Neurology. 2003;60(4):521-528.

44. Benedetti MD, Bower JH, Maraganore DM, et al. Smoking, alcohol, and coffee consumption preceding Parkinson's disease: a case-control study. Neurology. 2000;55(9):1350-1358.

45. Jimenez-Jimenez FJ, Mateo D, Gimenez-Roldan S. Premorbid smoking, alcohol consumption, and coffee drinking habits in Parkinson's disease: a case-control study. Mov Disord. 1992;7(4):339-344.

46. Brighina L, Schneider NK, Lesnick TG, et al. Alpha-synuclein, alcohol use disorders, and Parkinson disease: a case-control study. Parkinsonism Relat Disord. 2009;15(6):430-434.

47. Hernan MA, Logroscino G, Rodriguez LA. A prospective study of alcoholism and the risk of Parkinson's disease. J Neurol. 2004;251 Suppl 7:14-17.

48. Reichman ME, Judd JT, Longcope C, et al. Effects of alcohol consumption on plasma and urinary hormone concentrations in premenopausal women. J Nat Cancer Inst. 1993;85(9):722-727.

49. Purohit V. Moderate alcohol consumption and estrogen levels in postmenopausal women: a review. Alcohol Clin Exp Res. 1998;22(5):994-997.

50. Ginsburg ES, Walsh BW, Gao X, Gleason RE, Feltmate C, Barbieri RL. The effect of acute ethanol ingestion on estrogen levels in postmenopausal women using transdermal estradiol. J Soc Gynecol Investig. 1995;2(1):26-29.

51. Singletary KW, Gapstur SM. Alcohol and breast cancer: review of epidemiologic and experimental evidence and potential mechanisms. JAMA. 2001;286(17):2143-2151.

52. Whitton PS. Inflammation as a causative factor in the aetiology of Parkinson's disease. Br J Pharmacol. 2007;150(8):963-976. 


\section{Supplementary materials}

Table SI List of 202 morbidity categories and associated ICD-8 and ICD- 10 codes

Category
Cholera
Typhoid and paratyphoid fevers
Other intestinal infectious diseases
Shigellosis/Bacillary dysentery
Amoebiasis
Diarrhea and gastro-enteritis of presumed
infectious origin
Respiratory tuberculosis

Other tuberculosis

Plague

Other bacterial diseases

\section{Brucellosis}

Leprosy

Tetanus

Diphtheria

Whooping cough

Meningococcal infection

Septicemia

Early syphilis

ICD-codes

ICD-I0: A00.0-A00.9

ICD-8: 0.0-0.9

ICD-I0: A0I.0-A0I.9

ICD-8: I.0-I.9

ICD-8: 2.0-3.9

ICD- I0: A02.0-A02.9

ICD-I0: A04.0-A05.9

ICD-I0: A07.0-A08.9

ICD-8: 5.0-5.9

ICD-8: 7.0-7.9

ICD- I0: A03.0-A03.9

ICD-8: 4.0-4.9

ICD-I0: A06.0-A06.9

ICD-8: 6.0-6.9

ICD-I0: A09.0-A09.9

ICD-8: 8.0-9.9

ICD-I0: AI5.0-AI6.9

ICD-8: 10.0-12.3

ICD-8: 12.0-12.9

ICD-I0: AI7.0-AI9.9

ICD-I0: B90.0-B90.9

ICD-8: 13.0-19.9

ICD-I0: A20.0-A20.9

ICD-8: 20.0-20.9

ICD-10: A21.0-A22.9

ICD-10: A24.0-A28.9

ICD-I0: A31.0-A32.9

ICD-I0: A38.0-A38.9

ICD-I0: A42.0-A49.9

ICD-10: B96.0-B96.9

ICD-8: 21.0-22.9

ICD-8: 24.0-27.9

ICD-8: 3I.0-3I.9

ICD-8: 34.0-34.I

ICD-8: 35.0-35.9

ICD-8: 39.0-39.9

ICD-I0: A23.0-A23.9

ICD-8: 23.0-23.9

ICD- I0: A30.0-A30.9

ICD-I0: B92.0-B92.9

ICD-8: 30.0-30.9

ICD-I0: A33.0-A33.9

ICD-I0: A34.0-A35.9

ICD-8: 37.0-37.9

ICD-I0: A36.0-A36.9

ICD-8: 32.0-32.9

ICD- I0: A37.0-A37.9

ICD-8: 33.0-33.9

ICD- I0: A39.0-A39.9

ICD-8: 36.0-36.9

ICD- I0: A40.0-A4I.9

ICD-8: 38.0-38.9

ICD-10: A5I.0-A5I.9

ICD-8: 91.0-91.9
Table SI (Continued)

Other syphilis

ICD- I0: A50.0-A50.9

ICD-I0: A52.0-A53.9

ICD-8: 90.0-90.9

ICD-8: 92.0-97.9

Gonococcal infection

Other infectious and parasitic diseases

ICD- I0: A54.0-A54.9

ICD-8: 98.0-98.9

ICD-I0: A55.0-A67.9

ICD- I0: A69.0-A70.9

ICD-I0: A74.0-A74.9

ICD- I0: A77.0-A79.9

ICD-I0: B35.0-B49.9

ICD-I0: B58.0-B64.9

ICD- I0: B85.0-B89.9

ICD-I0: B94.0-B94.9

ICD- I0: B99.0-B99.9

ICD-8: I30.0-136.9

ICD-8: 89.0-89.9

ICD-8: 99.0-I।7.9

Relapsing fevers

Other viral diseases

ICD-10: A68.0-A68.9

ICD-8: 88.0-88.9

ICD-I0: A7I.0-A7I.9

ICD-I0: A8I.0-A8I.9

ICD-I0: A87.0-A89.9

ICD-I0: B00.0-B04.9

ICD- I0: B07.0-B09.9

ICD-I0: B20.0-B25.9

ICD-I0: B27.0-B34.9

ICD-I0: B97.0-B97.9

ICD-8: 45.0-46.9

ICD-8: 50.0-54.9

ICD-8: 57.0-57.9

ICD-8: 6I.0-6I.9

ICD-8: 66.0-66.9

ICD-8: 68.0-68.9

ICD-8: 73.0-79.9

ICD-I0: A75.0-A75.9

ICD-8: 80.0-83.9

ICD-I0: A80.0-A80.9

ICD-I0: B9I.0-B9I.9

ICD-8: 40.0-44.9

ICD-I0: A82.0-A82.9

ICD-8: 7I.0-7I.9

ICD-10: A83.0-A86.9

ICD-8: 62.0-65.9

ICD-10: A90.0-A94.9

ICD-I0: A96.0-A99.9

ICD-8: 67.0-67.9

ICD-I0: A95.0-A95.9

ICD-8: 60.0-60.9

ICD-I0: B05.0-B05.9

ICD-8: 55.0-55.9

ICD-I0: B06.0-B06.9

ICD-8: 56.0-56.9

ICD-I0: BI5.0-BI5.9

ICD-I0: B|6.0-BI6.9

ICD-I0: BI7.0-BI9.9

ICD-8: 70.0-70.9

(Continued) 
Table SI (Continued)

Category
Mumps
Malaria
Leishmaniasis
Trypanosomiasis
Schistosomiasis
Other helminthiases
Malignant neoplasm of other digestive
organs and peritoneum
Hookworm diseases/Ankylostomiasis
and pharynx

Malignant neoplasm of stomach

Malignant neoplasm of colon

Malignant neoplasm of rectosigmoid junction, rectum, anus and anal canal Other malignant neoplasms of respiratory and intrathoracic organs

Malignant neoplasm of other and unspecified respiratory organs

Malignant neoplasm of larynx

Malignant neoplasm of trachea, bronchus and lung

Malignant neoplasm of bone and articular cartilage

Malignant neoplasm of skin

Malignant neoplasm of other specified sites

Malignant neoplasm of breast

Other malignant neoplasms of female genital organs
ICD-codes

ICD-I0: B26.0-B26.9

ICD-8: 72.0-72.9

ICD- 10: B50.0-B54.9

ICD-8: 84.0-84.9

ICD- I0: B55.0-B55.9

ICD-8: 85.0-85.9

ICD-10: B56.0-B57.9

ICD-8: 86.0-87.9

ICD-10: B65.0-B65.9

ICD-8: $120.0-120.9$

ICD-10: B66.0-B66.9

ICD-10: B68.0-B75.9

ICD- I0: B77.0-B83.9

ICD-8: $|2| .0-121.9$

ICD-8: $\mid 23.0-125.9$

ICD-8: 127.0-129.9

ICD-I0: B67.0-B67.9

ICD-8: 122.0-122.9

ICD- I0: B76.0-B76.9

ICD-8: 126.0-126.9

ICD-I0: C00.0-CI4.9

ICD-8: I40.0-149.9

ICD-I0: CI5.0-CI5.9

ICD-I0: CI7.0-CI7.9

ICD-10: C22.0-C26.9

ICD-8: 150.0-150.9

ICD-8: 155.0-159.9

ICD-I0: $\mathrm{Cl} 6.0-\mathrm{Cl} 6.9$

ICD-8: I5I.0-I5I.9

ICD-10: CI8.0-CI8.9

ICD-8: I52.0-153.9

ICD-10: C19.0-C21.9

ICD-8: 154.0-154.9

ICD-10: C30.0-C3I.9

ICD-10: C37.0-C39.9

ICD-8: 160.0-160.9

ICD-8: 163.0-163.9

ICD-10: C32.0-C32.9

ICD-8: 161.0-161.9

ICD-10: C33.0-C34.9

ICD-8: I62.0-162.9

ICD- I0: C40.0-C4I.9

ICD-8: 170.0-170.9

ICD-10: C43.0-C43.9

ICD-10: C44.0-C44.9

ICD-8: 172.0-173.9

ICD- I0: C45.0-C49.9

ICD-10: C69.0-C70.9

ICD-10: C72.0-C72.9

ICD-8: $|7| .0-17 \mid .9$

ICD-8: $190.0-190.9$

ICD-8: 192.0-195.9

ICD- I0: C50.0-C50.9

ICD-8: 174.0-174.9

ICD-10: C5I.0-C52.9

ICD-10: C56.0-C58.9

ICD-8: $|8| .0-181.9$

ICD-8: $|83.0-183$.

ICD-8: $183.0-184.9$
Table SI (Continued)

Malignant neoplasm of cervix uteri

ICD- I0: C53.0-C53.9

ICD-8: 180.0-180.9

Malignant neoplasm of other and unspecified ICD-10: C54.0-C55.9

parts of uterus

Other malignant neoplasms of male genital organs

Malignant neoplasm of prostate

Other malignant neoplasms of urinary tract

Malignant neoplasm of other genitourinary organs

Malignant neoplasm of bladder

Malignant neoplasm of brain

Malignant neoplasm of other, ill-defined, secondary, unspecified and multiple sites

Hodgkin's disease

Other malignant neoplasms of lymphoid, hematopoietic and related tissue

Leukemia

Other in situ and benign neoplasms and neoplasms of uncertain and unknown behavior

Carcinoma in situ of cervix uteri

Benign neoplasm of skin

Leiomyoma of uterus

Benign neoplasm of ovary

Benign neoplasm of kidney and other urinary organs

Benign neoplasm of brain and other parts of central nervous system

Iron deficiency anemia
ICD-10: C60.0-C60.9

ICD-I0: C62.0-C63.9

ICD-8: $\mid 86.0-186.9$

ICD-10: C6I.0-C6I.9

ICD-8: 185.0-185.9

ICD-10: C64.0-C66.9

ICD-10: C68.0-C68.9

ICD-8: 187.0-187.9

ICD-8: $189.0-189.9$

ICD-10: C67.0-C67.9

ICD-8: 188.0-188.9

ICD-10: C7I.0-C7I.9

ICD-8: $191.0-191.9$

ICD-10: C73.0-C80.9

ICD-10: C97.0-C97.9

ICD-10: C81.0-C8I.9

ICD-8: 20I.0-20I.9

ICD-10: C82.0-C85.9

ICD-10: C88.0-C90.9

ICD- 10: C96.0-C96.9

ICD-8: 196.0-196.9

ICD-8: 200.0-200.9

ICD-8: 202.0-203.9

ICD-8: 208.0-209.9

ICD-10: C91.0-C95.9

ICD-8: 204.0-207.9

ICD-I0: D00.0-D05.9

ICD- 10: D07.0-D2I.9

ICD-10: D24.0-D24.9

ICD-I0: D26.0-D26.9

ICD- 10: D28.0-D29.9

ICD-10: D31.0-D32.9

ICD-10: D34.0-D48.9

ICD-8: 210.0-2I5.9

ICD-8: 217.0-217.9

ICD-8: 219.0-219.9

ICD-8: 22I.0-222.9

ICD-8: 224.0-224.9

ICD-8: 226.0-228.9

ICD-8: 230.0-239.9

ICD-10: D06.0-D06.9

ICD-10: D22.0-D23.9

ICD-8: 216.0-216.9

ICD-10: D25.0-D25.9

ICD-8: 218.0-218.9

ICD-I0: D27.0-D27.9

ICD-8: 220.0-220.9

ICD-10: D30.0-D30.9

ICD-8: 223.0-223.9

ICD- I0: D33.0-D33.9

ICD-8: 225.0-225.9

ICD- I0: D50.0-D50.9

ICD-8: 280.0-280.9
ICD-8: I82.0-182.9

ICD-8: 197.0-199.9

ICD-8: 234.0-234.0 
Table SI (Continued)

Category
Other anemias
Hemorrhagic conditions and other diseases
of blood and blood-forming organs
Other endocrine, nutritional and metabolic
disorders

Other disorders of thyroid

lodine-deficiency-related thyroid disorders

Diabetes mellitus

Avitaminosis and other nutritional deficiency

Dementia

Other mental and behavioral disorders

Alcohol-, drug-abuse-related disease

Schizophrenia, schizotypal and delusional disorders

Mood [affective] disorders

Depression

Neurotic, stress-related and somatoform disorders

Mental retardation

Inflammatory diseases of the central nervous system
ICD-codes

ICD-I0: D5I.0-D64.9

ICD-8: 28I.0-285.9

ICD-10: D65.0-D77.9

ICD-8: 286.0-289.9

ICD-10: D80.0-D89.9

ICD-I0: EI5.0-E35.9

ICD-I0: E58.0-E63.9

ICD-I0: E65.0-E65.9

ICD-I0: E66.0-E66.9

ICD-I0: E67.0-E85.9

ICD-I0: E87.0-E90.9

ICD-8: 25I.0-258.9

ICD-8: 270.0-279.9

ICD-I0: E03.0-E04.9

ICD-I0: E06.0-E07.9

ICD-8: 240.0-24I.9

ICD-8: 243.0-246.9

ICD-I0: E00.0-E02.9

ICD-I0: E05.0-E05.9

ICD-8: 242.0-242.9

ICD-I0: EI0.0-EI4.9

ICD-8: 249.0-250.9

ICD-I0: E40.0-E47.9

ICD-I0: E50.0-E50.9

ICD-I0: E5I.0-E56.9

ICD-I0: E64.0-E64.9

ICD-8: 260.0-269.9

ICD-I0: F00.0-F03.9

ICD-I0: G3I.0-G3I.0

ICD-8: 290.0-290.0

ICD-8: 290.0-290.9

ICD-I0: F04.0-F09.9

ICD-I0: F50.0-F69.9

ICD-I0: F80.0-F99.9

ICD-8: 292.0-294.9

ICD-8: 297.0-299.9

ICD-8: 305.0-309.9

ICD-I0: FI0.0-FI9.9

ICD-8: 29I.0-29I.9

ICD-8: 303.0-304.9

ICD-I0: F20.0-F29.9

ICD-8: 295.0-295.9

ICD-I0: F30.0-F3I.9

ICD-I0: F34.0-F39.9

ICD-8: 296.0-296.I

ICD-8: 296.0-296.9

ICD-I0: F32.0-F33.9

ICD-8: 296.0-296.0

ICD-8: 296.0-296.2

ICD-I0: F40.0-F48.9

ICD-8: 300.0-302.9

ICD-I0: F70.0-F79.9

ICD-8: 310.0-315.9

ICD-I0: G00.0-G09.9

ICD-8: 320.0-320.9

ICD-8: 321.0-324.9
Table SI (Continued)

Other diseases of the nervous system

ICD-I0: GI0.0-GI3.9

ICD-I0: G21.0-G26.9

ICD-I0: G3I.I-G32.9

ICD- I0: G36.0-G37.9

ICD- I0: G44.0-G44.9

ICD-I0: G46.0-G47.9

ICD-I0: G50.0-G73.9

ICD-I0: G80.0-G83.9

ICD-I0: G90.0-G99.9

ICD-8: 330.0-333.9

ICD-8: 343.0-344.9

ICD-8: 347.0-358.9

Parkinson's disease

Alzheimer's disease

Multiple sclerosis and other demyelinating disease

Epilepsy

Migraine

Transient cerebral ischemic attacks and related syndromes

Other inflammatory diseases of eye

Other diseases of the eye and adnexa

Cataract and other disorders of lens

Retinal detachments and breaks

Glaucoma

Strabismus

Other diseases of the ear and mastoid process

Acute rheumatic fever

Chronic rheumatic heart disease

Essential (primary) hypertension
ICD-I0: G20.0-G20.9

ICD-8: 342.0-342.9

ICD-I0: G30.0-G30.9

ICD-8: 290.0-290.।

ICD-I0: G35.0-G35.9

ICD-8: 340.0-34I.9

ICD- I0: G40.0-G4I.9

ICD-8: 345.0-345.9

ICD-8: 346.0-346.9

ICD- I0: G45.0-G45.9

ICD-8: 435.0-435.9

ICD-I0: H0O.0-H0I.9

ICD-I0: HIO.0-HI3.9

ICD-I0: HI5.0-HI9.9

ICD-8: 360.0-369.9

ICD-I0: H02.0-H06.9

ICD-I0: H20.0-H22.9

ICD-I0: H30.0-H32.9

ICD-I0: H34.0-H36.9

ICD- I0: H43.0-H48.9

ICD-I0: H5I.0-H59.9

ICD-8: 370.0-372.9

ICD-8: 377.0-379.9

ICD- I0: H25.0-H28.9

ICD-8: 374.0-374.9

ICD- I0: H33.0-H33.9

ICD-8: 376.0-376.9

ICD-I0: H40.0-H42.9

ICD-8: 375.0-375.9

ICD- I0: H49.0-H50.9

ICD-8: 373.0-373.9

ICD-I0: H60.0-H62.9

ICD- I0: H65.0-H75.9

ICD-I0: H80.0-H83.9

ICD-I0: H90.0-H95.9

ICD-8: 380.0-380.9

ICD-8: 381.0-381.9

ICD-8: 382.0-383.9

ICD-8: 384.0-389.9

ICD-I0: 100.0-102.9

ICD-8: 390.0-392.9

ICD-I0: 105.0-109.9

ICD-8: 393.0-398.9

ICD-10: II0.0-II5.9

ICD-8: 400.0-404.9
ICD- I0: G43.0-G43.9

(Continued) 
Table SI (Continued)

Category
Angina pectoris
Acute myocardial infarction
Other ischemic heart diseases
Other ischemic heart disease
Pulmonary embolism
Other heart diseases
Conduction disorders and cardiac
arrhythmias
Congestive heart failure
Intracranial hemorrhage
Cerebral infarction

Atherosclerosis
Other diseases of arteries, arterioles and
capillaries

Other peripheral vascular diseases

Phlebitis, thrombophlebitis, venous embolism and thrombosis

Varicose veins of lower extremities

Hemorrhoids

Other diseases of the circulatory system

Other acute upper respiratory infections

Acute pharyngitis and acute tonsillitis

Influenza

Pneumonia

Acute bronchitis and acute bronchiolitis
ICD-codes

ICD-I0: 120.0-120.9

ICD-8: 4|3.0-4|3.9

ICD-I0: I2I.0-I22.9

ICD-8: 410.0-410.9

ICD-I0: I23.0-I25.9

ICD-8: 4II.0-4I2.9

ICD-8: 4I4.0-4I4.9

ICD-I0: I26.0-I26.9

ICD-8: 450.0-450.9

ICD-I0: 127.0-I43.9

ICD-10: 15I.0-152.9

ICD-8: 420.0-426.9

ICD-8: 428.0-429.9

ICD-I0: 144.0-I49.9

ICD-8: 427.0-427.9

ICD-I0: I50.0-I50.9

ICD-8: 427.0-427.0

ICD-I0: 160.0-162.9

ICD-8: 43I.0-43I.9

ICD-I0: 163.0-163.9

ICD-8: 432.0-434.9

ICD-10: 164.0-164.9

ICD-I0: 165.0-169.9

ICD-8: 430.0-430.9

ICD-8: 436.0-436.9

ICD-8: 437.0-438.9

ICD-I0: 170.0-170.9

ICD-8: 440.0-440.9

ICD-I0: 17I.0-172.9

ICD-I0: 174.0-174.9

ICD- I0: 177.0-179.9

ICD-8: 44I.0-442.9

ICD-8: 444.0-448.9

ICD-I0: 173.0-173.9

ICD-8: 443.0-443.9

ICD-10: 180.0-182.9

ICD-8: 45I.0-453.9

ICD-I0: 183.0-183.9

ICD-8: 454.0-454.9

ICD-I0: 184.0-184.9

ICD-8: 455.0-455.9

ICD-10: 185.0-199.9

ICD-8: 456.0-458.9

ICD-I0: J00.0-J0I.9

ICD-I0: J04.0-J04.9

ICD-I0: J05.0-J06.9

ICD-8: 460.0-46I.9

ICD-8: 464.0-465.9

ICD-I0: J02.0-J03.9

ICD-8: 34.0-34.0

ICD-8: 462.0-463.9

ICD-I0: J 10.0-JII.9

ICD-8: 470.0-474.9

ICD-I0: J I2.0-JI8.9

ICD-8: $480.0-480.9$

ICD-8: 48I.0-48I.9

ICD-8: $482.0-483.9$

ICD-8: 484.0-486.9

ICD-I0: J20.0-J21.9

ICD-8: 466.0-466.9
Table SI (Continued)

Other diseases of the respiratory system

ICD- I0: J22.0-J22.9

ICD- I0: J66.0-J99.9

ICD-8: 510.0-5I4.9

ICD-8: 517.0-517.9

ICD-8: 519.0-519.9

Other diseases of upper respiratory tract

ICD-I0: J30.0-J3I.9

ICD- I0: J33.0-J34.9

ICD-I0: J36.0-J39.9

ICD-8: 501.0-502.9

ICD-8: 504.0-504.9

ICD-8: 505.0-508.9

Chronic sinusitis

Chronic disease of tonsils and adenoids

Bronchitis, emphysema and other chronic obstructive pulmonary diseases

Bronchiectasis

Pneumoconioses and related diseases

Other diseases of the teeth, oral cavity, salivary glands and jaws

Other diseases of esophagus, stomach and duodenum

ICD-I0: J32.0-J32.9

ICD-8: 503.0-503.9

ICD-I0: J35.0-J35.9

ICD-8: 500.0-500.9

ICD-I0: J40.0-J44.9

ICD-I0: J45.0-J46.9

ICD-8: 490.0-493.9

ICD-I0: J47.0-J47.9

ICD-8: 5I8.0-5I8.9

ICD- I0: J60.0-J65.9

ICD-8: 5I5.0-5I6.9

ICD-I0: K00.0-KI4.9

ICD-8: 520.0-529.9

ICD- 10: K20.0-K23.9

ICD- I0: K28.0-K28.9

ICD- I0: K30.0-K31.9

ICD-8: 530.0-530.9

ICD-8: 536.0-537.9

Gastric and duodenal ulcer

ICD- I0: K25.0-K27.9

ICD-8: 53I.0-534.9

ICD- I0: K29.0-K29.9

ICD-8: 535.0-535.9

ICD- I0: K35.0-K38.9

ICD-8: 540.0-543.9

ICD-10: K40.0-K46.9

ICD-8: 550.0-553.9

ICD- I0: K50.0-K51.9

ICD-8: 563.0-563.9

ICD- I0: K52.0-K55.9

ICD- 10: K57.0-K67.9

ICD- I0: K82.0-K83.9

ICD- I0: K87.0-K93.9

ICD-8: 561.0-562.9

ICD-8: 564.0-569.9

Paralytic ileus and intestinal obstruction without hernia

Other diseases of liver and gallbladder

ICD- I0: K56.0-K56.9

ICD-8: 560.0-560.9

ICD- I0: K70.0-K77.9

ICD-8: $570.0-573.9$

ICD-8: 576.0-576.9

Cholelithiasis and cholecystitis

ICD- 10: K80.0-K8I.9

ICD-8: 574.0-575.9

Acute pancreatitis and other diseases of the pancreas

Infections of the skin and subcutaneous

tissue

ICD- I0: K85.0-K86.9

ICD-8: 577.0-577.9

ICD- I0: L00.0-L08.9

ICD-8: 680.0-686.9

ICD-I0: LI0.0-L99.9

ICD-8: 690.0-698.9

ICD-8: 700.0-709.9 
Table SI (Continued)

Category
Other disorders of joints
Rheumatoid arthritis and other inflammatory
polyarthropathies

Osteoarthritis and allied conditions

Acquired deformities of limbs

Other diseases of the musculoskeletal system and connective tissue

Other dorsopathies

Osteochondrosis

Rheumatism

Cervical and other intervertebral disk disorders

Myositis

Soft tissue disorders

Osteoporosis with and without fracture

Other diseases of bone

Osteomyelitis and periostitis

Nephritis and nephrosis

Infections of kidney

Other diseases of the urinary system
ICD-codes

ICD- I0: M00.0-M03.9

ICD- I0: M22.0-M25.9

ICD-8: 724.0-724.9

ICD-8: 726.0-727.9

ICD-8: 729.0-729.9

ICD-8: 737.0-737.9

ICD-I0: M05.0-MI4.9

ICD-8: 7I2.0-7I2.9

ICD-8: 7|6.0-7I6.9

ICD-I0: MI5.0-MI9.9

ICD-I0: M47.0-M47.9

ICD-I0: M48.3-M48.3

ICD-8: 7I0.0-7II.9

ICD-8: 7|3.0-7|5.9

ICD-10: M20.0-M2I.9

ICD-8: 736.0-736.9

ICD-I0: M30.0-M36.9

ICD- I0: M87.0-M90.9

ICD- I0: M94.0-M99.9

ICD-8: 730.0-730.9

ICD-8: 733.0-734.9

ICD-8: 738.0-738.9

ICD-I0: M40.0-M4I.9

ICD-I0: M43.0-M43.5

ICD- I0: M43.7-M46.9

ICD-I0: M48.0-M48.2

ICD-I0: M48.4-M49.9

ICD- I0: M53.0-M53.9

ICD-8: 735.0-735.9

ICD-I0: M42.0-M42.9

ICD-I0: M9I.0-M93.9

ICD-8: 722.0-722.9

ICD-I0: M43.6-M43.6

ICD-I0: M79.0-M79.I

ICD-8: 7|7.0-7|8.9

ICD-I0: M50.0-M5I.9

ICD-I0: M54.0-M54.9

ICD-8: 725.0-725.9

ICD-8: 728.0-728.9

ICD- I0: M60.0-M60.9

ICD-8: 732.0-732.9

ICD-10: M6I.0-M78.9

ICD- I0: M79.2-M79.5

ICD-I0: M79.7-M79.9

ICD-8: 73।.0-73I.9

ICD- I0: M80.0-M8I.9

ICD-8: 723.0-723.0

ICD-10: M82.0-M85.9

ICD-8: 72I.0-72I.9

ICD-8: 723.0-723.9

ICD- I0: M86.0-M86.9

ICD-8: 720.0-720.9

ICD-I0: N00.0-N08.9

ICD-8: 580.0-584.9

ICD-I0: NI0.0-NI6.9

ICD-8: 590.0-590.9

ICD-I0: NI7.0-NI9.9

ICD-I0: N25.0-N29.9

ICD-I0: N3I.0-N39.9

ICD-8: 59I.0-59I.9
Table SI (Continued)

\begin{tabular}{|c|c|}
\hline & ICD-8: 593.0-593.9 \\
\hline & ICD-8: 596.0-599.9 \\
\hline \multirow[t]{3}{*}{ Urolithiasis/Calculus of urinary system } & ICD-I0: N20.0-N23.9 \\
\hline & ICD-8: 592.0-592.9 \\
\hline & ICD-8: 594.0-594.9 \\
\hline \multirow[t]{2}{*}{ Cystitis } & ICD-I0: N30.0-N30.9 \\
\hline & ICD-8: 595.0-595.9 \\
\hline \multirow[t]{2}{*}{ Hyperplasia of prostate } & ICD-I0: N40.0-N40.9 \\
\hline & ICD-8: 600.0-600.9 \\
\hline \multirow[t]{6}{*}{ Other diseases of male genital organs } & ICD-I0: N4I.0-N42.9 \\
\hline & ICD-I0: N44.0-N46.9 \\
\hline & ICD-I0: N48.0-N5I.9 \\
\hline & ICD-8: 60I.0-602.9 \\
\hline & ICD-8: 604.0-604.9 \\
\hline & ICD-8: 606.0-607.9 \\
\hline \multirow[t]{2}{*}{ Hydrocele and spermatocele } & ICD-I0: N43.0-N43.9 \\
\hline & ICD-8: 603.0-603.9 \\
\hline Redundant prepuce, phimosis and & ICD-I0: N47.0-N47.9 \\
\hline paraphimosis & ICD-8: 605.0-605.9 \\
\hline \multirow[t]{2}{*}{ Disorders of breast } & ICD-I0: N60.0-N64.9 \\
\hline & ICD-8: 6I0.0-6II.9 \\
\hline \multirow[t]{2}{*}{ Salpingitis and oophoritis } & ICD-I0: N70.0-N70.9 \\
\hline & ICD-8: 6I2.0-6I4.9 \\
\hline Other inflammatory diseases of female & ICD-I0: N7I.0-N7I.9 \\
\hline \multirow[t]{2}{*}{ pelvic organs } & ICD-I0: N73.0-N77.9 \\
\hline & ICD-8: 622.0-622.9 \\
\hline \multirow[t]{2}{*}{ Inflammatory disease of cervix uteri } & ICD-I0: N72.0-N72.9 \\
\hline & ICD-8: 620.0-620.9 \\
\hline \multirow[t]{2}{*}{ Endometriosis } & ICD-I0: N80.0-N80.9 \\
\hline & ICD-8: 625.0-625.3 \\
\hline \multirow[t]{2}{*}{ Female genital prolapse } & ICD-I0: N8I.0-N8I.9 \\
\hline & ICD-8: 623.0-623.9 \\
\hline \multirow[t]{8}{*}{ Other disorders of genitourinary tract } & ICD-I0: N82.0-N82.9 \\
\hline & ICD-I0: N84.0-N90.9 \\
\hline & ICD-I0: N93.0-N96.9 \\
\hline & ICD-I0: N98.0-N99.9 \\
\hline & ICD-8: 62I.0-62I.9 \\
\hline & ICD-8: 624.0-625.9 \\
\hline & ICD-8: 627.0-627.9 \\
\hline & ICD-8: 629.0-629.9 \\
\hline \multirow{2}{*}{$\begin{array}{l}\text { Other diseases of ovary, fallopian tube and } \\
\text { parametrium }\end{array}$} & ICD-I0: N83.0-N83.9 \\
\hline & ICD-8: 6I5.0-6I6.9 \\
\hline \multirow[t]{2}{*}{ Disorders of menstruation } & ICD-I0: N9I.0-N92.9 \\
\hline & ICD-8: 626.0-626.9 \\
\hline \multirow[t]{2}{*}{ Female infertility } & ICD-I0: N97.0-N97.9 \\
\hline & ICD-8: 628.0-628.9 \\
\hline \multirow[t]{2}{*}{ Ectopic pregnancy } & ICD-I0: O00.0-O00.9 \\
\hline & ICD-8: 63I.0-63I.9 \\
\hline \multirow[t]{2}{*}{ Pregnancies with abortive outcome } & ICD-I0: O0I.0-O08.9 \\
\hline & ICD-8: 640.0-645.9 \\
\hline \multirow{7}{*}{$\begin{array}{l}\text { Other complications of pregnancy or } \\
\text { delivery }\end{array}$} & ICD-I0: OI0.0-OI6.9 \\
\hline & ICD-I0: O20.0-O48.9 \\
\hline & ICD-I0: O60.0-O75.9 \\
\hline & ICD-I0: O8I.0-099.9 \\
\hline & ICD-8: 630.0-639.9 \\
\hline & ICD-8: 65I.0-666.9 \\
\hline & ICD-8: 670.0-678.9 \\
\hline
\end{tabular}


Table SI (Continued)

Category
Delivery without mention of complication
Conditions originating in the perinatal
period
Hemolytic disease of fetus and newborn
Spina bifida and congenital hydrocephalus
Congenital malformations of the circulator
system
Cleft lip and cleft palate
Other congenital malformations of the
digestive system

Absence, atresia and stenosis of small intestine

Other malformations of the genitourinary system
ICD-codes

ICD-I0: 080.0-080.9

ICD-8: 650.0-650.9

ICD- 10: P00.0-P54.9

ICD-I0: P56.0-P96.9

ICD-8: $760.0-773.9$

ICD-8: 776.0-779.9

ICD- I0: P55.0-P55.9

ICD-8: 774.0-775.9

ICD- 10: Q05.0-Q05.9

ICD-8: 74I.0-742.9

ICD-10: Q20.0-Q28.9

ICD-8: 746.0-747.9

ICD-10: Q35.0-Q37.9

ICD-8: 749.0-749.9

ICD-10: Q38.0-Q40.9

ICD- I0: Q42.0-Q45.9

ICD-8: $750.0-750.0$

ICD-8: $750.0-750.9$

ICD-8: 75I.0-75I.9

ICD-10: Q4I.0-Q4I.9

ICD-8: 750.0-750.I

ICD- 10: Q50.0-Q52.9

ICD-10: Q54.0-Q64.9

ICD-8: 752.2-753.9
Table SI (Continued)

Undescended testicle

ICD-I0: Q53.0-Q53.9

ICD-8: 752.0-752.I

Congenital deformities of hip

ICD-I0: Q65.0-Q65.9

Congenital deformities of feet

ICD-8: 755.0-755.6

ICD- I0: Q66.0-Q66.9

ICD-8: 754.0-754.9

Other congenital malformations and

deformations of the musculoskeletal system

ICD-I0: Q67.0-Q79.9

ICD-8: 755.0-755.9

ICD-8: 755.0-756.9

ICD-8: 756.0-756.9

Other and unspecified congenital anomalies

ICD-I0: Q00.0-Q04.9

ICD-I0: Q06.0-Q07.9

ICD-I0: Q10.0-Q18.9

ICD-I0: Q30.0-Q34.9

ICD-I0: Q80.0-Q99.9

ICD-8: 740.0-740.9

ICD-8: 743.0-745.9

ICD-8: 748.0-748.9

ICD-8: 757.0-759.9

Abdominal and pelvic pain

ICD-I0: RI0.0-RI0.9

ICD-8: 785.0-785.5

ICD- I0: R54.0-R54.9

ICD-8: 794.0-794.9

(Continued) 
Table S2 All 147 morbidity categories with 5 or more cases of PD are shown with the number of exposed cases, original OR and $P$-value, and EB adjusted odds ratio and $P$-value

\begin{tabular}{|c|c|c|c|c|c|}
\hline Category & \# Cases & $\begin{array}{l}\text { Original } \\
\text { OR }\end{array}$ & $\begin{array}{l}\text { Original } \\
P \text {-value }\end{array}$ & $\begin{array}{l}\text { Adjusted } \\
\text { OR }\end{array}$ & $\begin{array}{l}\text { Adjusted } \\
P \text {-value }\end{array}$ \\
\hline Neurotic, stress-related and somatoform disorders & 278 & 2.35 & $<0.0001$ & 2.16 & $1.5 \times 10^{-7}$ \\
\hline Other diseases of the nervous system & 314 & 1.64 & $<0.0001$ & 1.59 & 0.001 \\
\hline Depression & 77 & 2.02 & $<0.0001$ & 1.7 & 0.001 \\
\hline Alcohol-, drug-abuse-related disease & 104 & 1.85 & $<0.0001$ & 1.65 & 0.002 \\
\hline Rheumatism & 327 & 1.56 & $<0.0001$ & 1.52 & 0.004 \\
\hline Other mental and behavioral disorders & 99 & 1.72 & $<0.0001$ & 1.56 & 0.006 \\
\hline Mood [affective] disorders & 34 & 2.37 & $<0.0001$ & 1.65 & 0.006 \\
\hline Cystitis & 307 & 1.52 & $<0.000$ I & 1.48 & 0.006 \\
\hline Mental retardation & 22 & 3.15 & $<0.0001$ & 1.68 & 0.007 \\
\hline Acute pancreatitis and other diseases of the pancreas & 62 & 1.84 & $<0.0001$ & 1.57 & 0.008 \\
\hline Epilepsy & 95 & 1.67 & $<0.0001$ & 1.52 & 0.009 \\
\hline Angina pectoris & 326 & 1.48 & $<0.000$ I & 1.45 & 0.01 \\
\hline Other diseases of the circulatory system & 51 & 1.8 & 0.0001 & 1.52 & 0.016 \\
\hline lodine-deficiency-related thyroid disorders & 210 & 1.45 & $<0.000$ I & 1.41 & 0.02 \\
\hline Diabetes mellitus & 303 & $1.4 \mathrm{I}$ & $<0.000$ I & 1.39 & 0.023 \\
\hline Respiratory tuberculosis & 27 & 2.12 & 0.0004 & 1.53 & 0.024 \\
\hline Other ischemic heart diseases & 396 & 1.37 & $<0.000$ I & 1.36 & 0.031 \\
\hline Other infectious and parasitic diseases & 64 & 1.58 & 0.0007 & 1.44 & 0.032 \\
\hline Other endocrine, nutritional and metabolic disorders & 302 & 1.38 & $<0.0001$ & 1.36 & 0.034 \\
\hline Other diseases of liver and gallbladder & 95 & $\mathrm{I} .48$ & 0.0004 & 1.4 & 0.037 \\
\hline Migraine & 75 & 1.52 & 0.0009 & 1.41 & 0.038 \\
\hline Gastritis and duodenitis & 171 & 1.39 & $<0.0001$ & 1.36 & 0.042 \\
\hline Disorders of menstruation & 802 & 1.32 & $<0.0001$ & 1.32 & 0.045 \\
\hline Other diseases of esophagus stomach and duodenum & 177 & 1.36 & 0.0001 & 1.34 & 0.053 \\
\hline Congenital malformations of the circulatory system & 16 & 2.27 & 0.003 & 1.46 & 0.053 \\
\hline Nephritis and nephrosis & 19 & 2.06 & 0.0042 & 1.45 & 0.054 \\
\hline Inflammatory diseases of the central nervous system & 22 & 1.93 & 0.0048 & 1.44 & 0.054 \\
\hline Congestive heart failure & 155 & 1.36 & 0.0004 & 1.33 & 0.06 \\
\hline Infections of the skin and subcutaneous tissue & 109 & 1.39 & 0.0014 & 1.35 & 0.061 \\
\hline Dementia & 53 & 1.5 & 0.006 & 1.38 & 0.062 \\
\hline Strabismus & 33 & 1.59 & 0.0134 & 1.39 & 0.074 \\
\hline Other diseases of the digestive system & 556 & 1.29 & $<0.0001$ & 1.28 & 0.074 \\
\hline Diarrhea and gastro-enteritis of presumed infectious origin & 106 & 1.35 & 0.0036 & 1.32 & 0.08 \\
\hline Influenza & 45 & 1.47 & 0.0167 & 1.35 & 0.086 \\
\hline Avitaminosis and other nutritional deficiency & 22 & 1.7 & 0.0217 & 1.38 & 0.088 \\
\hline Acute pharyngitis and acute tonsillitis & 21 & 1.72 & 0.0221 & 1.38 & 0.089 \\
\hline Other tuberculosis & 20 & 1.73 & 0.0237 & 1.38 & 0.092 \\
\hline Other disorders of genitourinary tract & 229 & 1.28 & 0.0005 & 1.28 & 0.098 \\
\hline Other disorders of thyroid & 259 & 1.28 & 0.0002 & 1.27 & 0.099 \\
\hline Other anemias & 100 & 1.32 & 0.0086 & 1.3 & 0.102 \\
\hline Malignant neoplasm of other and unspecified parts of uterus & 108 & 1.32 & 0.0073 & 1.3 & 0.103 \\
\hline Abdominal and pelvic pain & 213 & 1.27 & 0.0011 & 1.27 & 0.113 \\
\hline Essential (primary) hypertension & 458 & 1.25 & $<0.0001$ & 1.25 & 0.113 \\
\hline Other diseases of the urinary system & 189 & 1.27 & 0.0019 & 1.27 & 0.115 \\
\hline Iron deficiency anemia & 65 & 1.33 & 0.03 & 1.3 & 0.124 \\
\hline Benign neoplasm of brain and other parts of central nervous system & 31 & 1.43 & 0.062 & 1.32 & 0.132 \\
\hline Conditions originating in the perinatal period & 7 & 2.55 & 0.0303 & 1.36 & 0.133 \\
\hline Endometriosis & 42 & 1.37 & 0.0551 & 1.3 & 0.134 \\
\hline Transient cerebral ischemic attacks and related syndromes & 144 & 1.26 & 0.01 & 1.25 & 0.142 \\
\hline Gastric and duodenal ulcer & 278 & 1.23 & 0.0012 & 1.23 & 0.151 \\
\hline $\begin{array}{l}\text { Malignant neoplasm of other, ill-defined, secondary, unspecified, multiple } \\
\text { sites }\end{array}$ & 25 & 1.42 & 0.0999 & 1.31 & 0.155 \\
\hline Malignant neoplasm of bladder & 22 & $\mathrm{I} .44$ & 0.1074 & 1.31 & 0.158 \\
\hline
\end{tabular}


Table S2 (Continued)

\begin{tabular}{|c|c|c|c|c|c|}
\hline Category & \# Cases & $\begin{array}{l}\text { Original } \\
\text { OR }\end{array}$ & $\begin{array}{l}\text { Original } \\
\text { P-value }\end{array}$ & $\begin{array}{l}\text { Adjusted } \\
\text { OR }\end{array}$ & $\begin{array}{l}\text { Adjusted } \\
\text { P-value }\end{array}$ \\
\hline $\begin{array}{l}\text { Hemorrhagic conditions and other diseases of blood and blood-forming } \\
\text { organs }\end{array}$ & 34 & 1.35 & 0.1043 & 1.29 & 0.166 \\
\hline Hemorrhoids & 155 & 1.23 & 0.0168 & 1.23 & 0.176 \\
\hline Septicemia & 31 & 1.34 & 0.125 & 1.28 & 0.176 \\
\hline Other congenital malformations of the digestive system & 12 & 1.58 & 0.1397 & 1.31 & 0.177 \\
\hline Other inflammatory diseases of female pelvic organs & 87 & 1.25 & 0.0519 & 1.24 & 0.178 \\
\hline Other viral diseases & 89 & 1.24 & 0.0565 & 1.24 & 0.186 \\
\hline Other peripheral vascular diseases & 26 & 1.35 & 0.1562 & 1.28 & 0.188 \\
\hline Other diseases of bone & 26 & 1.34 & 0.1574 & 1.28 & 0.188 \\
\hline Soft tissue disorders & 219 & 1.21 & 0.0096 & 1.21 & 0.192 \\
\hline Hernia & 296 & 1.2 & 0.0032 & 1.21 & 0.194 \\
\hline Pulmonary embolism & 50 & 1.26 & 0.1288 & 1.25 & 0.202 \\
\hline Leukemia & 10 & 1.52 & 0.2144 & 1.29 & 0.207 \\
\hline Other diseases of the eye and adnexa & 264 & 1.19 & 0.0083 & 1.2 & 0.216 \\
\hline Malignant neoplasm of stomach & II & 1.45 & 0.2499 & 1.28 & 0.217 \\
\hline Acute rheumatic fever & 8 & 1.56 & 0.2437 & 1.29 & 0.218 \\
\hline Cervical and other intervertebral disk disorders & 377 & 1.18 & 0.0027 & 1.19 & 0.227 \\
\hline Acute bronchitis and acute bronchiolitis & 51 & 1.23 & 0.1642 & 1.23 & 0.227 \\
\hline Acute poliomyelitis & 8 & 1.5 & 0.2839 & 1.28 & 0.229 \\
\hline Female genital prolapse & 582 & 1.18 & 0.0003 & 1.18 & 0.232 \\
\hline $\begin{array}{l}\text { Other malignant neoplasms of lymphoid, hematopoietic } \\
\text { and related tissue }\end{array}$ & 38 & 1.23 & 0.2248 & 1.23 & 0.239 \\
\hline Osteomyelitis and periostitis & 14 & 1.32 & 0.3293 & 1.26 & 0.244 \\
\hline Malignant neoplasm of colon & 73 & 1.2 & 0.1426 & 1.21 & 0.245 \\
\hline Schizophrenia, schizotypal and delusional disorders & 9 & 1.4 & 0.348 & 1.26 & 0.246 \\
\hline Malignant neoplasm of other specified sites & 17 & 1.28 & 0.3412 & 1.25 & 0.251 \\
\hline Other dorsopathies & 63 & 1.2 & 0.1802 & 1.21 & 0.255 \\
\hline Chronic disease of tonsils and adenoids & 14 & 1.29 & 0.3818 & 1.25 & 0.259 \\
\hline Conduction disorders and cardiac arrhythmias & 326 & 1.17 & 0.0092 & 1.18 & 0.26 \\
\hline Other intestinal infectious diseases & 8 & 1.33 & 0.4449 & 1.25 & 0.269 \\
\hline Other diseases of the ear and mastoid process & 379 & 1.16 & 0.0085 & 1.17 & 0.271 \\
\hline Phlebitis, thrombophlebitis, venous embolism and thrombosis & 133 & 1.17 & 0.0871 & 1.19 & 0.272 \\
\hline Other diseases of the musculoskeletal system and connective tissue & 154 & 1.17 & 0.0752 & 1.18 & 0.28 \\
\hline Cataract and other disorders of lens & 451 & 1.15 & 0.006 & 1.16 & 0.289 \\
\hline Pneumonia & 264 & 1.16 & 0.029 & 1.17 & 0.293 \\
\hline Other bacterial diseases & 56 & 1.17 & 0.274 & 1.2 & 0.297 \\
\hline Other inflammatory diseases of eye & 62 & 1.16 & 0.2832 & 1.19 & 0.313 \\
\hline Other malformations of the genitourinary system & 24 & 1.16 & 0.4998 & 1.21 & 0.32 \\
\hline Inflammatory disease of cervix uteri & 21 & 1.16 & 0.5317 & 1.21 & 0.322 \\
\hline Benign neoplasm of kidney and other urinary organs & 32 & 1.14 & 0.4716 & 1.19 & 0.331 \\
\hline Malignant neoplasm of other genitourinary organs & 12 & 1.14 & 0.6703 & 1.21 & 0.332 \\
\hline Ectopic pregnancy & II & 1.14 & 0.6928 & 1.21 & 0.332 \\
\hline Leiomyoma of uterus & 226 & 1.14 & 0.0711 & 1.15 & 0.333 \\
\hline Female infertility & 13 & 1.11 & 0.7316 & 1.2 & 0.35 \\
\hline Hepatitis & 5 & I & 0.9949 & 1.21 & 0.364 \\
\hline Malignant neoplasm of skin & 68 & 1.12 & 0.3765 & 1.16 & 0.371 \\
\hline Disorders of breast & 170 & 1.12 & 0.1573 & 1.14 & 0.375 \\
\hline Bronchiectasis & 5 & 0.95 & 0.9209 & 1.2 & 0.379 \\
\hline Other diseases of ovary, fallopian tube and parametrium & 79 & 1.11 & 0.3682 & 1.15 & 0.386 \\
\hline Urolithiasis/Calculus of urinary system & 101 & 1.12 & 0.2983 & 1.15 & 0.387 \\
\hline Malignant neoplasm of trachea, bronchus and lung & 13 & 1.04 & 0.8886 & 1.18 & 0.393 \\
\hline Typhoid and paratyphoid fevers & 5 & 0.86 & 0.7477 & 1.19 & 0.412 \\
\hline Benign neoplasm of ovary & 108 & 1.11 & 0.3277 & 1.14 & 0.413 \\
\hline Other in situ and benign neoplasms or of uncertain/unknown behavior & 596 & 1.11 & 0.0191 & 1.12 & 0.42 \\
\hline Other diseases of upper respiratory tract & 95 & 1.1 & 0.3793 & 1.14 & 0.42 \\
\hline
\end{tabular}


Table S2 (Continued)

\begin{tabular}{|c|c|c|c|c|c|}
\hline Category & \# Cases & $\begin{array}{l}\text { Original } \\
\text { OR }\end{array}$ & $\begin{array}{l}\text { Original } \\
P \text {-value }\end{array}$ & $\begin{array}{l}\text { Adjusted } \\
\text { OR }\end{array}$ & $\begin{array}{l}\text { Adjusted } \\
P \text {-value }\end{array}$ \\
\hline $\begin{array}{l}\text { Other congenital malformations/deformations } \\
\text { of the musculoskeletal system }\end{array}$ & 22 & 1.05 & 0.8351 & 1.16 & 0.422 \\
\hline Glaucoma & III & 1.09 & 0.3709 & 1.13 & 0.44 \\
\hline Intracranial hemorrhage & 19 & I & 0.9909 & 1.15 & 0.457 \\
\hline Other cerebrovascular diseases & 219 & 1.09 & 0.2137 & I.II & 0.464 \\
\hline Diseases of appendix & 119 & 1.08 & 0.416 & 1.12 & 0.475 \\
\hline Chronic sinusitis & 18 & 0.97 & 0.8932 & 1.14 & 0.488 \\
\hline Acute myocardial infarction & 235 & 1.09 & 0.2379 & I.II & 0.493 \\
\hline Multiple sclerosis and other demyelinating disease & 13 & 0.91 & 0.737 & 1.14 & 0.5 \\
\hline Other diseases of the skin and subcutaneous tissue & 183 & $\mathrm{I} .08$ & 0.3258 & I.II & 0.501 \\
\hline Carcinoma in situ of cervix uteri & 53 & 1.05 & 0.7547 & 1.12 & 0.501 \\
\hline Cerebral infarction & 102 & 1.07 & 0.5218 & I.II & 0.502 \\
\hline Malignant neoplasm of lip, oral cavity and pharynx & 7 & 0.77 & 0.4979 & 1.15 & 0.503 \\
\hline Other complications of pregnancy or delivery & 133 & 1.06 & 0.6019 & I.II & 0.506 \\
\hline Osteochondrosis & 21 & 0.95 & 0.8228 & 1.13 & 0.533 \\
\hline Other diseases of the teeth, oral cavity, salivary glands and jaws & 76 & $\mathrm{I} .04$ & 0.7218 & I.II & 0.544 \\
\hline Malignant neoplasm of breast & 211 & 1.07 & 0.3679 & 1.09 & 0.548 \\
\hline Salpingitis and oophoritis & 20 & 0.93 & 0.7426 & 1.12 & 0.554 \\
\hline Other heart diseases & 77 & 1.04 & 0.7586 & I.I & 0.562 \\
\hline Acquired deformities of limbs & 31 & 0.97 & 0.8887 & I.II & 0.564 \\
\hline Osteoarthritis and allied conditions & 692 & 1.07 & 0.0898 & 1.08 & 0.568 \\
\hline Cholelithiasis and cholecystitis & 383 & 1.07 & 0.232 & 1.08 & 0.576 \\
\hline Other and unspecified congenital anomalies & 26 & 0.95 & 0.7927 & I.II & 0.576 \\
\hline Chronic rheumatic heart disease & 24 & 0.94 & 0.7585 & I.II & 0.577 \\
\hline Other diseases of the respiratory system & 90 & 1.03 & 0.7592 & 1.09 & 0.588 \\
\hline Varicose veins of lower extremities & 347 & 1.06 & 0.3149 & 1.08 & 0.605 \\
\hline Other acute upper respiratory infections & 23 & 0.91 & 0.6469 & I.I & 0.617 \\
\hline Infections of kidney & 76 & 1.02 & 0.8962 & 1.09 & 0.62 \\
\hline Other diseases of arteries, arterioles and capillaries & 97 & 0.84 & 0.0963 & 0.93 & 0.673 \\
\hline Benign neoplasm of skin & 31 & 0.91 & 0.6085 & 1.08 & 0.688 \\
\hline Retinal detachments and breaks & 23 & 0.59 & 0.014 & 0.93 & 0.699 \\
\hline Rheumatoid arthritis and other inflammatory polyarthropathies & 119 & 1.01 & 0.9178 & 1.06 & 0.704 \\
\hline Malignant neoplasm of rectosigmoid junction, rectum, anus, anal canal & 29 & 0.89 & 0.5322 & 1.07 & 0.713 \\
\hline Atherosclerosis & 89 & 0.99 & 0.9518 & 1.06 & $0.7 \mid 4$ \\
\hline Other disorders of joints & 128 & I & 0.9646 & 1.05 & 0.736 \\
\hline Osteoporosis with and without fracture & 108 & 0.99 & 0.8846 & 1.05 & 0.776 \\
\hline Malignant neoplasm of cervix uteri & 25 & 0.65 & 0.0346 & 0.95 & 0.79 \\
\hline Other malignant neoplasms of female genital organs & 25 & 0.82 & 0.35 & 1.05 & 0.79 \\
\hline Crohn's disease and ulcerative colitis & 36 & 0.88 & 0.4703 & 1.05 & 0.792 \\
\hline $\begin{array}{l}\text { Bronchitis, emphysema and other chronic } \\
\text { obstructive pulmonary diseases }\end{array}$ & 238 & I & 0.9632 & 1.03 & 0.824 \\
\hline Delivery without mention of complication & 72 & 0.92 & 0.5339 & 1.04 & 0.839 \\
\hline Paralytic ileus and intestinal obstruction without hernia & 61 & 0.92 & 0.5124 & $\mathrm{I} .03$ & 0.871 \\
\hline Pregnancies with abortive outcome & 119 & 0.94 & $0.57 \mid I$ & 1.02 & 0.922 \\
\hline
\end{tabular}

Abbreviations: OR, odds ratio; PD, Parkinson's disease; EB, empirical Bayes.

Clinical Epidemiology

\section{Publish your work in this journal}

Clinical Epidemiology is an international, peer-reviewed, open access journal focusing on disease and drug epidemiology, identification of risk factors and screening procedures to develop optimal preventative initiatives and programs. Specific topics include: diagnosis, prognosis, treatment, screening, prevention, risk factor modification, systematic

Submit your manuscript here: http://www.dovepress.com/clinical-epidemiology-journal reviews, risk \& safety of medical interventions, epidemiology \& biostatical methods, evaluation of guidelines, translational medicine, health policies \& economic evaluations. The manuscript management system is completely online and includes a very quick and fair peer-review system, which is all easy to use. 